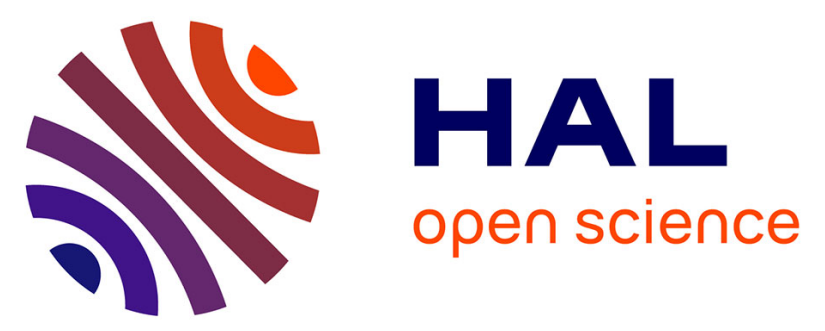

\title{
Optimization of an inductively coupled plasma etching process of GaInP/GaAs based material for photonic band gap applications
}

Sylvain Combrié, Shailendra Bansropun, Michel Lecomte, Olivier Parillaud, Simone Cassette, Henri Benisty, Julien Nagle

\section{To cite this version:}

Sylvain Combrié, Shailendra Bansropun, Michel Lecomte, Olivier Parillaud, Simone Cassette, et al.. Optimization of an inductively coupled plasma etching process of $\mathrm{GaInP} / \mathrm{GaAs}$ based material for photonic band gap applications. Journal of Vacuum Science and Technology, 2005, 23 (4), pp.15211526. 10.1116/1.1993617. hal-00903584

\section{HAL Id: hal-00903584 \\ https://hal-iogs.archives-ouvertes.fr/hal-00903584}

Submitted on 12 Nov 2013

HAL is a multi-disciplinary open access archive for the deposit and dissemination of scientific research documents, whether they are published or not. The documents may come from teaching and research institutions in France or abroad, or from public or private research centers.
L'archive ouverte pluridisciplinaire HAL, est destinée au dépôt et à la diffusion de documents scientifiques de niveau recherche, publiés ou non, émanant des établissements d'enseignement et de recherche français ou étrangers, des laboratoires publics ou privés. 


\title{
Optimization of an inductively coupled plasma etching process of GalnP/GaAs based material for photonic band gap applications*
}

\author{
S. Combriéa) \\ Thales Research and Technology, Domaine de Corbeville 91404 Orsay, \\ and Laboratoire Charles Fabry de l'Institut d'Optique, Bat 503, 91403 Orsay, France \\ S. Bansropun \\ Thales Research and Technology, Domaine de Corbeville, 91404 Orsay, France \\ M. Lecomte and O. Parillaud \\ Thales Research and Technology, Domaine de Corbeville, 91404 Orsay \\ and Alcatel-Thales III-V Lab, Domaine de Corbeville, 91404 Orsay, France \\ S. Cassette \\ Thales Research and Technology, Domaine de Corbeville, 91404 Orsay, France \\ H. Benisty \\ Laboratoire Charles Fabry de l'Institut d' Optique, Băt 503, 91403 Orsay, France \\ J. Nagle \\ Thales Research and Technology, Domaine de Corbeville, 91404 Orsay, France
}

(Received 25 February 2005; accepted 13 June 2005; published 20 July 2005)

\begin{abstract}
In this article, we investigate the dry etching of $\mathrm{GaInP} / \mathrm{GaAs}$ based material system using an inductively coupled plasma (ICP) etching system. In a view to develop a suitable ICP process for the etching of aluminum-free material, ridge waveguides have been fabricated and the effects of the ICP parameters have been assessed. The coil power and the platen power have been varied at constant pressure and temperature for a chlorine-based process. The surface quality, sidewall profile, and selectivity have been reported. We also demonstrate the optimization of the chlorine-based process for deep etching and its subsequent implementation in photonic band gap device fabrication for $1.55 \mu \mathrm{m}$ optical applications. The optimized process has been shown to provide a high aspect ratio and a good selectivity for $250 \mathrm{~nm}$ diam holes with a depth of $3 \mu \mathrm{m}$ in the GaInP/GaAs material system. The influence of the ICP parameters on this material system have been analyzed mainly by scanning electron microscopy with particular attention drawn to the ways of reducing trenching, an effect commonly associated with ICP etching. () 2005 American Vacuum Society.
\end{abstract}

[DOI: $10.1116 / 1.1993617$ ]

\section{INTRODUCTION}

The fabrication of most optoelectronic devices necessitates pattern transfer techniques with a good control of both structure size and shape. While the current etching technologies satisfy the demands of the optoelectronics industry to realize feature sizes of several microns with high performance, there are, however, a number of issues, such as homogeneity and full-wafer reproducibility, which need to be addressed for submicronic devices. Recently, the requirements became more important with the resurgence of structures requiring straight profiles with deep etch and very smooth surfaces in dimensions on the order of hundreds of nanometers; e.g., photonic band gap devices ${ }^{1}$ which are particularly demanding in this respect. Among the different dry etching methods available, inductively coupled plasma (ICP) seems to be the most appropriate candidate with its large flexibility for plasma control and uniformity. It is possible, unlike a reactive ion etch (RIE) system, to control indepen-

\footnotetext{
*No proof corrections received from author prior to publication.
}

${ }^{a)}$ Electronic mail: sylvain.combrie@thalesgroup.com dently the density of the plasma and the energy of the ions to achieve large etch rates without significant crystallographic damage $^{2}$ for a wide range of materials.

The recent technological evolution in the field of dry etching, in particular with the use of the ICP, has shown tremendous results. Important advances have already been demonstrated in this field with $\mathrm{InP}_{-}{ }^{2,3}$ and $\mathrm{GaAs}_{-}{ }^{4}$ based materials. One of the main challenges, however, remains the fabrication of photonic band gap structures where the main difficulty lies in the realization of $<300 \mathrm{~nm}$ wide features several $\mu \mathrm{m}$ deep with vertical sidewalls and smooth surface. The material investigated in this article is GaInP lattice matched on GaAs with a view to working in an aluminum-free regime for future photonic devices.

GaInP lattice matched to GaAs has been proposed as an alternative to GaAlAs for both electronic ${ }^{5-7}$ and optical devices. ${ }^{8-11}$ The GaInP/GaAs material system has a larger valence band discontinuity ${ }^{6}$ and a lower surface recombination velocity ${ }^{12}$ than $\mathrm{AlGaAs} / \mathrm{GaAs}$. This results in higher emitter injection efficiency and higher device gain in the case of heterojunction bipolar transistors. ${ }^{5}$ Another important characteristic of the GaInP/GaAs material system is its lack 
of $D X$ centers. Typically, $D X$ centers cause the shift of threshold voltage with temperature, hence causing low temperature instability for high electron mobility transistors ${ }^{7}$ at low temperatures where device performance is expected to be superior. As for optoelectronic devices, aluminum-free lasers offer several advantages in the $980 \mathrm{~nm}$ wavelength range. These include lower facet heating and damage, low electrical and thermal resistance, easier regrowth possibilities, and high reliability particularly for high power performance.

However, the main difficulty with this material system is the etching of the GaInP compared to GaAlAs ${ }^{13}$ due to higher average bond energy and formation of low volatile reaction products $\mathrm{InCl}_{x}$ when using a chlorine-based chemistry. The main difficulties with dry etching InP-based compounds are the low etch rates, preferential loss of material, and subsequently rough surfaces. Wet etching is traditionally preferred for the GaInP/GaAs material block mainly because of the good etching selectivity of GaInP with respect to GaAs, but it cannot be used to achieve straight profiles in nanometric devices. GaInP etching has already been investigated and reported in electron cyclotron resonance, ${ }^{14}$ reactive ion beam etching, ${ }^{15} \mathrm{RIE},{ }^{16}$ and $\mathrm{ICP}^{13,17,18}$ techniques with satisfactory results. Past approaches include methane/ hydrogen, methane/hydrogen/chlorine, chlorine/argon. A $\mathrm{CH}_{4} / \mathrm{H}_{2}$ chemistry for ICP dry etching is complicated by slow etch rates and polymer formation. Hydrocarbon species in this chemistry tend to form a polymer on the sidewalls, which acts to protect them. Excessive polymer buildup can however cause severe deterioration. Cycles of etch and clean using an oxygen plasma is usually favored to avoid any excessive polymer buildup. Although good surface quality can be obtained with these etchants, chamber conditioning and polymer desorption can affect reproducibility.

The process proposed in this article is a "clean" process (i.e., hydrocarbon free) based on a $\mathrm{Cl}_{2} / \mathrm{N}_{2}$ chemistry. ${ }^{19}$ It is common knowledge that chlorine chemistry has its own drawbacks, namely the need to use elevated temperature for etching the less volatile $\mathrm{InCl}_{x}$. An appropriate volatility of the reaction products at the etched surface is preferable since nonvolatile surface products prevent etching. A chlorine chemistry also requires significant ion bombardment to obtain acceptable surface morphology. High temperature and substantial ion bombardment stretch the limits of the mask used, hence affecting its selectivity. With a $\mathrm{Cl}_{2} / \mathrm{N}_{2}$ process, however, neither chamber conditioning nor polymer cleaning is required between etching, but a high reproducibility is obtained instead. This article describes the influence of the coil and platen power of an ICP on the surface morphology, sidewall quality, and etch profile of ridge waveguides realized from a GaInP/GaAs material system. It also investigates means to suppress the "trenching effect" commonly associated with a high bombardment plasma regime. It also provides a satisfactory ICP process reproducible on photonic band gap devices.

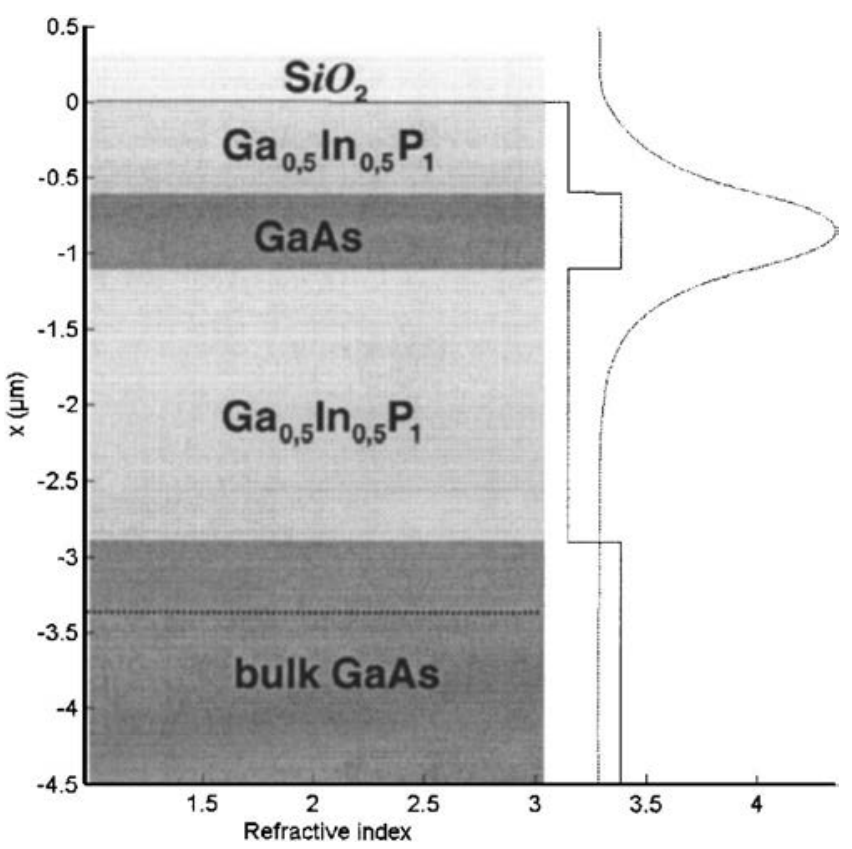

FIG. 1. Nominal wafer structure, index profile, and respective modal waveguide (TE polarization).

\section{EPITAXIAL GROWTH AND FABRICATION}

The layer structure reported in this article has been designed for $1.55 \mu \mathrm{m}$ optical applications. It consists of a $500 \mathrm{~nm}$ undoped GaAs core layer sandwiched between undoped GaInP top and bottom cladding layers of, respectively, $600 \mathrm{~nm}$ and $1.8 \mu \mathrm{m}$. The epitaxial layers have been grown by metalorganic chemical vapor deposition on GaAs $n+$ doped substrate. Figure 1 shows the nominal wafer structure with the corresponding index and waveguide mode [transverse electric (TE) polarization] profiles, respectively.

Since typical photoresist cannot withstand the temperature of the plasma $\left(>150{ }^{\circ} \mathrm{C}\right)$, a hard mask has been used instead. The hard mask used in this article is $\mathrm{SiO}_{2}$. Although the $\mathrm{SiO}_{2}$ mask is prone to erosion under high temperature processes, it also has the advantage of easy patterning and RIE etching with well defined profiles, which is crucial to ensure good sidewall quality and verticality. $400 \mathrm{~nm}$ of $\mathrm{SiO}_{2}$ was first deposited by plasma enhanced chemical vapor deposition. The thickness of the silica layer was measured using a Jobin-Yvon/Horiba UVISEL-460 spectroscopic ellipsometer. Conventional optical photolithography was then used to transfer the test patterns, typically $1 \mu \mathrm{m}$ wide ridge structures, onto the silica mask. RIE with a $\mathrm{CHF}_{3} / \mathrm{O}_{2}$ plasma was used to etch the $\mathrm{SiO}_{2}$ for pattern definition.

ICP etching of the material was performed in a STS Multiplex system comprised of a single wafer loadlock and a single ICP processing module. The substrate platen is driven at $13.56 \mathrm{MHz}$ and the inductive coil power is simultaneously driven by a generator at $13.56 \mathrm{MHz}$. To etch the indium based compounds, the temperature of the ceramic sample holder was maintained constant above $150{ }^{\circ} \mathrm{C}$ and at a constant pressure of $5 \mathrm{mT}$. No thermal conduction paste was used but, helium backfill was utilized to provide good ther- 


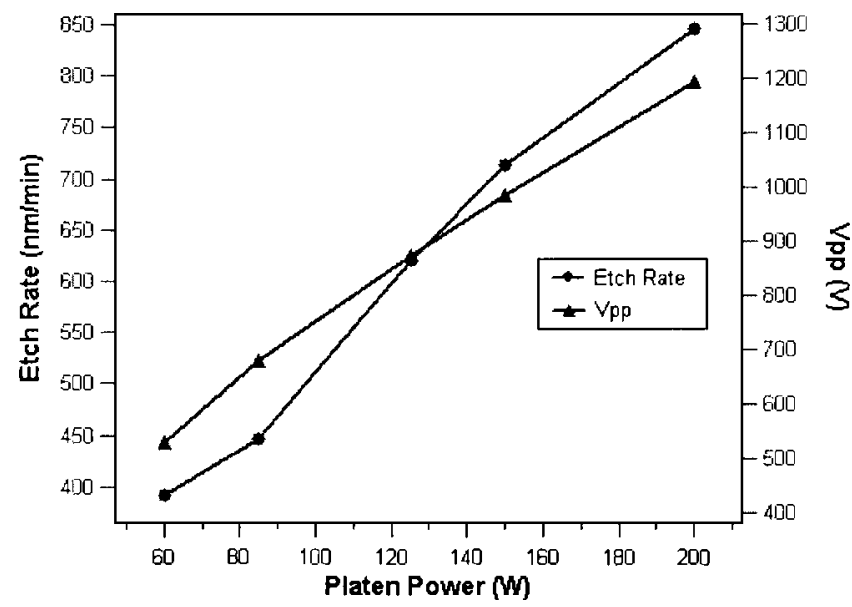

FIG. 2. Etch rate (nm/min) of GaInP and $V_{\text {peak-to-peak }}$ as a function of applied platen rf power.

mal contact to the carrier backside, hence enabling substrate temperature control. Based on previous experience with this material system, a mixture of $\mathrm{Cl}_{2} / \mathrm{N}_{2}$, in the ratio $1: 4$, was deemed suitable for this particular process chemistry. For all the tests described in this article, the same sample size was used and the etch time was controlled using an end-point detection system. The $\mathrm{Cl}_{2} / \mathrm{N}_{2}$ composition ratio (1:4) was the same throughout for comparative analysis. With the conditions as such, the two main parameters under investigation are the inductive coil power $\left(P_{c}\right)$ and the platen power $\left(P_{p}\right)$. $P_{c}$, which generates most of the plasma and enables high density plasma at low pressure, has a direct impact on the chemical aspect of the plasma. $P_{p}$ is related to the ions flux and the speed at which they impinge on the surface. Surface analysis and etch profile were inspected under a scanning electron microscope (SEM).

\section{RESULTS AND DISCUSSIONS}

\section{A. Influence of the platen power}

The influence of the platen power was studied by keeping the pressure, the temperature, and plasma chemistry constant. For a $\mathrm{Cl}_{2} / \mathrm{N}_{2}$ chemistry with a fixed 1:4 ratio, the process was operated at a pressure of $5 \mathrm{mT}$ and $P_{c}$ arbitrarily fixed at $600 \mathrm{~W}$ as a starting point. $P_{p}$ was then varied over a range of 60-200 W. Figure 2 shows the linear variation of the etch rate with $P_{p}$ and the peak-to-peak voltage $V_{\mathrm{pp}} . V_{\mathrm{pp}}$ is the magnitude of the rf voltage seen at the surface of the platen or wafer and it increases with the platen power. On this particular system, $V_{\mathrm{pp}}$ is a self-adjusting parameter and cannot be controlled. Instead, it provides a very good estimate of the reproducibility of the process and indicates the type of etch taking place. The linear rise of the etch rate with $P_{p}$ describes a more physical, desorption-limited etch mechanism ${ }^{17}$ rather than a regime with high ion density.

Figures 3(a) and 3(b) show typical SEM pictures of a ridge waveguide etched with the platen power at 85 and $150 \mathrm{~W}$, respectively. The important characteristics observed are the undercut in the GaAs core layer (zone A) and the

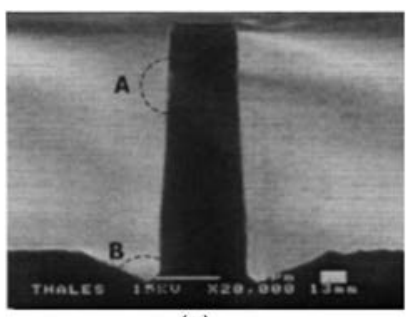

(a)

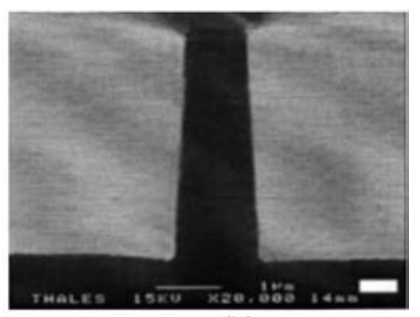

(b)
FIG. 3. SEM pictures of a ridge waveguide etched with the platen power at $85 \mathrm{~W}$ (a) and $150 \mathrm{~W}$ (b). The coil power in both cases is $600 \mathrm{~W}$. The important characteristics observed in (a) are the undercut in the GaAs corelayer (zone A) and the deep trenching at the end of etch (zone B).

deep trenching, of almost $1 \mu \mathrm{m}$, observed at the end of etch (zone B) in Fig. 3(a). The profile is slightly slanted in the bottom GaInP layer. The slight roughness at the end of etch is mainly due to the transition between GaInP and GaAs buffer layers. The verticality of the profile improves with increase in $P_{p}$ together with a decrease in trenching and a better surface quality at the end of etch. This can be explained by the fact that any increase in platen power implies an increase in $V_{\mathrm{pp}}$. This is translated into an increase in the acceleration of the ions towards the platen. Directionality is improved, hence the verticality. Increasing the platen power is also synonymous of a more physical and less chemical behavior of the plasma. This is confirmed by the reduction of the undercut in the GaAs layer.

\section{B. Influence of the coil power}

The influence of the coil power, with all other parameters kept constant, will now be discussed. With the platen power fixed at $150 \mathrm{~W}$, the coil power was varied between 150 and $900 \mathrm{~W}$ in an attempt to find a suitable compromise between surface quality and selectivity. ICP coil power controls the dissociation of the plasma and the incident ion flux, hence an expected impact on the chemical aspect of the etch. Figure 4 shows the variation of the etch rate with coil power where an

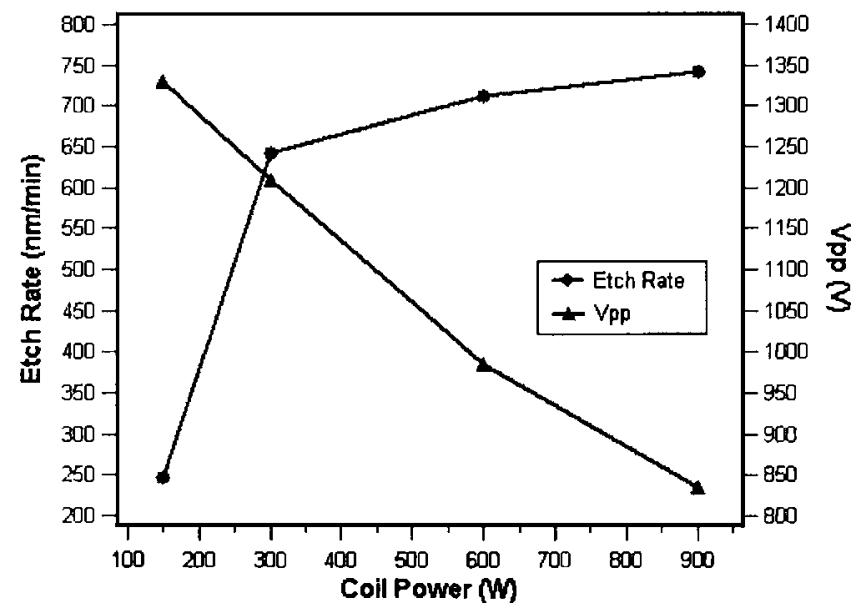

FIG. 4. Etch rate $(\mathrm{nm} / \mathrm{min})$ and $V_{\text {peak-to-peak }}$ as a function of applied coil power. 


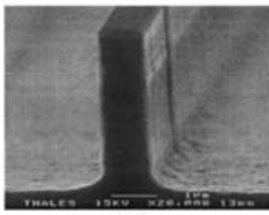

(a)

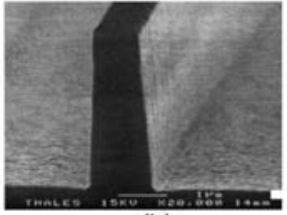

(b)

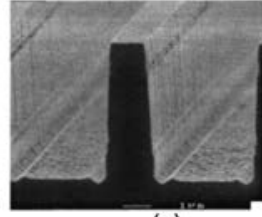

(c)
FIG. 5. SEM pictures for the etched ridge waveguides with $P_{c}$ varied over (a) $300 \mathrm{~W}$, (b) $600 \mathrm{~W}$, and (c) $900 \mathrm{~W}$, respectively. The platen power is fixed at $150 \mathrm{~W}$. The etch profile shows a transition between an etch foot and a trench with coil power variation.

increase in etch rate is observed for increasing $P_{c}$. The etch rate is dependent on both the surface chemical reactivity as well as the physical sputtering mechanisms responsible for the removal of species at the surface. It can be observed that below a coil power of $300 \mathrm{~W}$, the etch rate is low. Above $300 \mathrm{~W}$, the etch rate is important and tends to grow steadily with the coil power. The low etch rate for a plasma process with $P_{c}$ at $150 \mathrm{~W}$ and $P_{p}$ at $150 \mathrm{~W}$ can be attributed to the limited dissociation of the plasma species. Hence, there is a lack of chemical reactants for any significant etching to take place.

Figures 5(a)-5(c) show SEM pictures for the etched ridge waveguides with $P_{c}$ varied over 300,600 , and $900 \mathrm{~W}$, respectively. It can be observed that at $300 \mathrm{~W}$, the profile is vertical with the presence of an etch foot. The transition between the GaInP and GaAs layers in the heterostructure occurs without any deterioration. As $P_{c}$ increases, the etch foot is gradually eliminated, but at $900 \mathrm{~W}$, both chemical underetching in the GaAs layer and a trench start to appear. The slanted profiles of Figs. 5(b) and 5(c) also confirm a more chemical plasma reaction for higher coil power.

\section{Study of the "trenching" effect}

Another common aspect of the ICP etching is the term known as trenching usually associated with a plasma regime with significant ion bombardment, typical of a $\mathrm{N}_{2}$-based plasma chemistry. Trenching can have different origins and a common explanation is a reflection of the ions on the sidewalls. The ions reflected off the sidewalls come into collision with the foot of the ridge. In this particular zone, there is then a combined effect of two sources of ions, i.e., ions resulting from reflections and ions impinging directly at normal incidence. We thus observe a more important etch in that area giving rise to a trenching effect. In this case, the higher the energy of the ions, i.e., higher $P_{p}$, the deeper the trench. Experimentally, however, the opposite effect is observed with these plasma parameters, as shown in Figs. 3(a) and 3(b).

Another origin of trenching can be the effect of charge buildup. Electrons, because of their high diffusivity and longer mean free path, tend to preferentially charge the upper salient portions of etched features and resist regions. As a result, ions are bent towards the sidewalls, which can result in trenching. The larger the energy of the ions, the more their trajectories are rectilinear, leading to a more uniform distri-

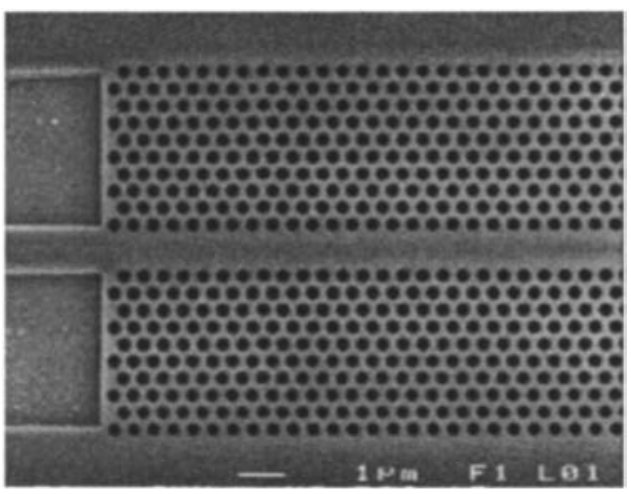

FIG. 6. SEM picture of the photonic crystal waveguide between the two arrays two of holes in the $\mathrm{SiO}_{2}$ layer after $\mathrm{CHF}_{3}$ plasma etching.

bution of the density of ions, and, thus, a more uniform etching. With an increase in platen power, the trench decreases. An increase of the coil power implies a decrease in ion energy leading to a less directional trajectory. A rise in coil power also leads to a higher number of dissociated atoms and thus more free electrons. A direct consequence of these combined effects is the accumulation of charges in the upper part of the etched features causing more ion deflection and more trenching. This is observed in Figs. 5(a)-5(c) where the etch profile shows a transition between an etch foot and a trench with coil power variation. It can be deduced that the trenching effect is more a consequence of the charge buildup rather than the ion reflection in this particular case.

\section{Optimum conditions for photonic crystals fabrication}

The main requirement for photonic crystal fabrication is the deep etching of small features with a straight profile. The conditions that lead to the above effects are affected to a possibly larger extent by the confined etching geometry. In practice, the above choice for the best conditions has been based on several considerations, namely profile selectivity, surface quality, trenching effect at the end of etch, and verticality. For wide patterns as described previously, it can be

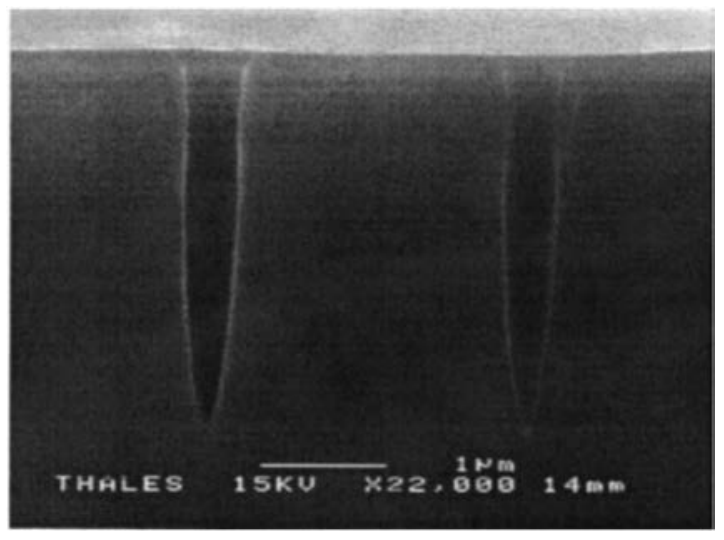

FIG. 7. SEM picture of the cross section of the photonic crystal in the $\mathrm{GaInP} / \mathrm{GaAs} / \mathrm{GaInP}$ material. 


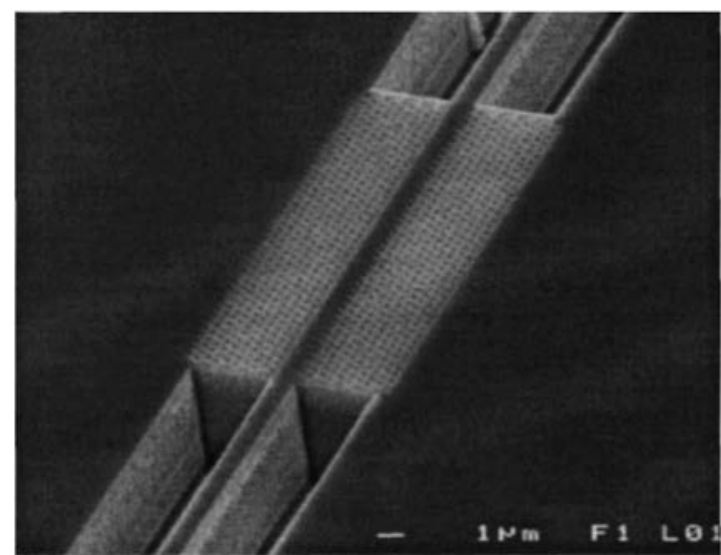

FIG. 8. SEM picture of the complete device with ridge (bottom and top), PBG (center) waveguide.

confirmed that the optimum conditions for this particular $\mathrm{Cl}_{2} / \mathrm{N}_{2}$ process are obtained for a platen and a coil power fixed, respectively, at 150 and $600 \mathrm{~W}$ with a pressure of $5 \mathrm{mT}$ and a temperature above $150{ }^{\circ} \mathrm{C}$. This process optimized for ridge waveguide structures was nonetheless applied to photonic band gap devices with the same epitaxial wafer structure. The design used in this article was based mainly on the integration of two arrays of holes with a fixed diameter of $250 \mathrm{~nm}$, defining a photonic crystal waveguide, in between two ridge waveguide structures. For a diameter of $250 \mathrm{~nm}$, an expected etch depth of $3 \mu \mathrm{m}$ through the $\mathrm{GaInP} / \mathrm{GaAs} / \mathrm{GaInP}$ material is required for minimal losses and adequate waveguiding ${ }^{20}$ as illustrated by the modal behavior in Fig. 1.

The fabrication process for these photonic devices is similar to the processing detailed in Sec. II. The definition of the holes has been carried out using electron-beam lithography. Even though recent advances in optical lithography have shown the possibility of using deep ultraviolet lithography ${ }^{21}$ for the definition of devices sizes $<200 \mathrm{~nm}$, electron-beam lithography has been the preferred choice in our case. A $400 \mathrm{~nm}$ mask of $\mathrm{SiO}_{2}$ was used as a hard mask and poly(methyl methacrylate) (PMMA) was used as photoresist for electron-beam lithography. A PMMA thickness of $400 \mathrm{~nm}$ was chosen to ensure sufficient durability as a mask for RIE pattern transfer onto $400 \mathrm{~nm}$ of $\mathrm{SiO}_{2}$ and simultaneously for highest resolution for $e$-beam writing and proper definition of the $250 \mathrm{~nm}$ holes as shown in Fig. 6.

Figures 7 and 8 illustrate the SEM pictures of the etched samples. A straight profile with a smooth transition between the GaInP and GaAs can be observed. No undercut is observed in the layers indicating a suitable $\mathrm{Cl}_{2} / \mathrm{N}_{2}$ chemistry for the etching of $\mathrm{GaInP}$ and $\mathrm{GaAs}$ material systems. The important consideration here is the profile perfect verticality in the first $1.8 \mu \mathrm{m}$, which is very good for expected optical properties. ${ }^{1}$ A vertical profile has been achieved for the holes with an etched depth of $3 \mu \mathrm{m}$ and a selectivity of 15 with respect to the $\mathrm{SiO}_{2}$ mask.

\section{CONCLUSIONS}

In conclusion, we have studied the dry etching of ridge waveguides using GaInP/GaAs epitaxial structure, with potential applications in fabricating aluminum-free optoelectronic devices. The influence of the coil and platen power of an inductively coupled plasma etching system has been assessed and a process has been developed for photonic band gap devices, and compatible for ridge-based devices as well. Improvement of the verticality of the profile and better end of etch surface quality have been obtained. The trenching effect commonly associated with a $\mathrm{N}_{2}$-based ICP etching has been investigated and its elimination by the variation of the coil and platen power has been observed. A smooth transition between the GaInP and GaAs layers has been observed, indicating a suitable chlorine chemistry for this particular material system. The effect of varying the coil power and platen power in the chlorinated-based process on trenching has also been investigated, its mechanisms discussed, and careful optimization has proved successful. Using the optimized process, photonic band gap devices have been fabricated with the hole diameter as low as $250 \mathrm{~nm}$ with an etched depth of $3 \mu \mathrm{m}$ with a satisfactory aspect ratio and a straight vertical profile.

\section{ACKNOWLEDGMENTS}

The authors would like to thank A. De Rossi, M. Garcia, M. Laurent, P. Plouhinec, J.-L. Reverchon, L. Teisseire, and F. VanDijk for their technical assistance. They would also like to thank K. Griffiths and A. Barker from STS Company Limited for their support. The authors are also grateful to Véronique Mathet and Abdelhanin Aassime from l'Institut d'Electronique Fondamentale (IEF) at Orsay for their support and helpful advice.

${ }^{1}$ R. Ferrini, R. Houdré, H. Benisty, M. Qiu, and J. Moosburger, J. Opt. Soc. Am. B 20, 469 (2003).

${ }^{2}$ J. Etrillard, J. F. Bresse, C. Daguet, M. Riet, and J. Mba, J. Vac. Sci. Technol. A 17, 1174 (1999).

${ }^{3}$ S. L. Rommel et al., J. Vac. Sci. Technol. B 20, 1327 (2002).

${ }^{4}$ W. T. Lim, I. K. Baek, J. W. Lee, M. H. Jeon, W. W. Park, G. S. Cho, and S. J. Pearton, J. Electrochem. Soc. 151, 343 (2004).

${ }^{5}$ T. Oka, K. Hirata, H. Suzuki, K. Ouchi, H. Uchiyama, T. Taniguchi, K. Mochizuki, and T. Nakamura, Electron Devices 48, 2625 (2001).

${ }^{6}$ M. S. Faleh, J. Tasselli, J. P. Bailbe, and A. Marty, Appl. Phys. Lett. 69, 1288 (1996).

${ }^{7}$ M. Chertouk, S. Bürkner, K. Bachem, W. Pletschen, S. Kraus, J. Braunstein, and G. Tränkle, Electron. Lett. 34, 590 (1998).

${ }^{8}$ S. Rusli, A. Al-Muhanna, T. Earles, and L. J. Mawst, Electron. Lett. 36, 630 (2000).

${ }^{9}$ M. Ohkubo, T. Ijichi, A. Iketani, and T. Kikuta, Quantum Electron. 30, 406 (1994).

${ }^{10}$ Y. H. Chen, C. I. Wilkinson, J. Woodhead, J. P. R. David, C. C. Button, and P. N. Robson, Photonics Technol. Lett. 9, 143 (1997).

${ }^{11}$ C.-S. Jiang, H. R. Moutinho, J. F. Geisz, D. J. Friedman, and M. M. Al-Jassim, Appl. Phys. Lett. 81, 2569 (2002).

${ }^{12}$ J. M. Olson, R. K. Ahrenkiel, D. J. Dunlavy, B. Keyes, and A. E. Kibbler, Appl. Phys. Lett. 55, 1208 (1989).

${ }^{13}$ I. K. Baek, W. T. Lim, J. W. Lee, M. H. Jeon, G. S. Cho, and S. J. Pearton, J. Vac. Sci. Technol. B 21, 2487 (2003).

${ }^{14}$ R. J. Shul, R. P. Schneider Jr., and C. Constantine, Electron. Lett. 30, 817 (1994).

${ }^{15}$ T. Yoshikawa, Y. Sugimoto, H. Yoshii, H. Kawano, S. Kohmoto, and K. 
Asakawa, Electron. Lett. 29, 190 (1993).

${ }^{16}$ B. Saint-Cricq, A. Sadeghi, A. Rudra, and M. Ilegems, Mater. Sci. Eng., B 28, 365 (1994).

${ }^{17}$ J. Hong, J. W. Lee, C. R. Abernaty, E. S. Lambers, and S. J. Pearton, J. Vac. Sci. Technol. A 16, 1497 (1998).

${ }^{18}$ D. C. Hays et al., Appl. Surf. Sci. 156, 76 (2000).
${ }^{19}$ D. J. Thomas et al., Proceedings GaAs Mantech 2001, p. 172.

${ }^{20}$ H. Benisty, P. Lalanne, S. Olivier, M. Rattier, C. Weisbuch, C. J. M. Smith, T. F. Krauss, C. Jouanin, and D. Cassagne, Opt. Quantum Electron. 34, 205 (2002).

${ }^{21}$ W. Bogaerts, V. Wiaux, D. Taillaert, S. Beckx, B. Luyssaert, P. Bienstman, and R. Baets, IEEE J. Sel. Top. Quantum Electron. 8, 4 (2002). 